\title{
Biotransformation of Flavonoids Improves Antimicrobial and Anti-Breast Cancer Activities In Vitro
}

\author{
Yanpeng Hao ${ }^{1}$, Zuchen Wei ${ }^{1,2}$, Zhi Wang ${ }^{1}$, Guiying Li $^{1}$, Yang Yao ${ }^{1} \mathbb{D}$ and Baoqing Dun ${ }^{1, *}$ \\ 1 Institute of Crop Science, Chinese Academy of Agricultural Sciences, No. 80 South Xueyuan Road, \\ Haidian District, Beijing 100081, China; haoyanpeng@caas.cn (Y.H.); weizuchen@163.com (Z.W.); \\ wangzhi@caas.cn (Z.W.); liguiying@caas.cn (G.L.); yaoyang@caas.cn (Y.Y.) \\ 2 Laboratory for Green Cultivation and Deep Processing of Three Gorges Reservoir Area's Medicinal Herbs, \\ College of Life Science \& Engineering, The Chongqing Engineering, Chongqing Three Gorges University, \\ No. 666 Tianxing Road, Wanzhou District, Chongqing 404000, China \\ * Correspondence: dunbaoqing@caas.cn
}

Citation: Hao, Y.; Wei, Z.; Wang, Z.;

Li, G.; Yao, Y.; Dun, B.

Biotransformation of Flavonoids Improves Antimicrobial and

Anti-Breast Cancer Activities In Vitro. Foods 2021, 10, 2367. https://doi.org/ $10.3390 /$ foods 10102367

Academic Editor: Cornelia Witthöft

Received: 16 September 2021

Accepted: 30 September 2021

Published: 5 October 2021

Publisher's Note: MDPI stays neutral with regard to jurisdictional claims in published maps and institutional affiliations.

Copyright: (C) 2021 by the authors. Licensee MDPI, Basel, Switzerland. This article is an open access article distributed under the terms and conditions of the Creative Commons Attribution (CC BY) license (https:// creativecommons.org/licenses/by/ $4.0 /)$

\begin{abstract}
Coarse cereals are rich in flavonoids, which are bioactive substances with a wide range of functions. Biotransformation is considered an emerging approach to methylate flavonoids, displaying prominent regio- and stereoselectivity. In the current study, liquiritigenin, naringenin, and hesperidin flavonoids were biotransformed using $O$-methyltransferases that were heterologously expressed in Saccharomyces cerevisiae BJ5464-NpgA. Nuclear magnetic resonance (NMR) spectroscopy was used together with high-resolution mass spectroscopy analysis to determine the structures of the resulting methylated transformants, and their antimicrobial and antiproliferation activities were also characterized. Among the five methylated flavonoids obtained, 7-methoxy-liquiritigenin had the strongest inhibitory effect on Candida albicans SC5314 (C. albicans SC5314), Staphylococcus aureus ATCC6538 (S. aureus ATCC6538), and Escherichia coli ATCC25922 (E. coli ATCC25922), which increased 7.65-, 1.49-, and 0.54-fold in comparison to the values of their unmethylated counterparts at 200, 250 , and $400 \mu \mathrm{M}$, respectively. The results suggest that $3^{\prime}$-methoxyhesperetin showed the best antiproliferative activity against MCF-7 cells with $\mathrm{IC}_{50}$ values of $10.45 \pm 0.45 \mu \mathrm{M}$, which was an increase of more than 14.35-fold compared to that of hesperetin. These results indicate that methylation enhances the antimicrobial activities and antiproliferative effects of flavonoids. The current study provides an experimental basis for further research on flavonoids as well as flavonoidcontaining crops in the development of antimicrobial and anti-breast cancer drugs in addition to supplementary and health foods. The biotransformation method is ideal, as it represents a means for the sustainable production of bioactive flavonoids.
\end{abstract}

Keywords: flavonoids; biotransformation; methylation; antimicrobial; anti-breast cancer

\section{Introduction}

Flavonoids are a type of plant secondary metabolite that are widely present in many minor grains, such as Tartary buckwheat, quinoa, and barley [1-3]. In addition to being diverse in variety, flavonoids also possess complex structure types, and they perform many bioactive functions, including antioxidation effects [4,5], antiproliferative effects [6], and antibacterial effects $[7,8]$. Flavonoids have been commonly used in bacteriostatic therapy and are considered to possess the potential to replace some antibiotics; quercetin, for example, similarly to existing antibiotics, has the potential to treat Pseudomonas aeruginosa infection and its use as an alternative may help to ease the selection pressure due to antibiotic overuse [9]. However, many natural flavonoids present many disadvantages, such as low content, poor water solubility, and unstable bioavailability. For example, adverse reactions caused by puerarin have been reported in its clinical application, including fever, allergies, and hemolysis [10], which are related to its poor solubility and low bioavailability. There- 
fore, the use of current technology has been applied to address these problems through the development of derivatives via structural modification.

The main methods of structural modification include the introduction of halogen or other active groups. Common active groups are methyl, acyl, and glycosyl. Acylation modification can affect the ability of flavonoid to attack free radicals and regulate its interaction with proteins, enzymes, and specific cells [11], subsequently improving their antioxidation [12,13], anti-inflammatory, and other lipid-lowering [14] abilities. The introduction of different active groups into flavonoids can change the conformation of flavonoids, enhance their biological activity, and even produce new physiological functions. Methylquercetin metabolized in filamentous fungi showed lower cytotoxicity on leukemic HL-60 cells than quercetin [15]. Moreover, in an in vivo study on drug-resistant seizures, $4^{\prime}, 7$-dimethyl ether naringenin performed better than naringenin [16].

At present, chemical catalysis and biocatalysis are emerging methods used to modify flavonoid structure. Biocatalysis methods mainly use enzymes secreted by microorganisms, while chemical catalysis is carried out via specific chemical reactions. Biocatalysis is considered to be green and eco-friendly technology, which has sustainable development prospects [17]. Since 2000, a variety of microorganisms have exhibited abilities to convert flavonoids, and some microorganisms were also found to naturally and directly synthesize flavonoids as a result of their own endogenous metabolism [18]. The biocatalytic production of flavonoids offers many advantages, such as fast production, low environmental pollution, and large-scale production. However, there is a scarcity of research on flavonoid biocatalysis and the bioactivity of the resulting product.

Therefore, the aim of the current work was to determine whether biocatalytic methods can be used to achieve methylation modification of flavonoids and to characterize the potential improvement in the biological activity, structural stability, and bioavailability of these methylated products. This study contributes to realizing the green, economic, fast, efficient, and sustainable development of the production of bioactive flavonoids.

\section{Materials and Methods}

\subsection{Chemicals and Regents}

Primary samples (liquiritigenin, naringenin, and hesperetin) and other compounds were all obtained from Shanghai Yuanye Bio-Technology Co., Ltd. (Shanghai, China). All media components were provided by Clontech Laboratories, Inc. (Los Angeles, CA, USA). Methylene blue, Luria-Bertani medium, and potato dextrose broth medium were purchased from BD-Pharmingen (San Diego, CA, USA). Other reagents were of analytical grade.

\subsection{Biotransformation Procedures}

Biotransformation procedures were performed in a laboratory according to the methods of Wang et al. [19]. Briefly, the Saccharomyces cerevisiae BJ5464-NpgA strain was used for to host the plasmids YEpADH2-LEU-HsOMT and YEpADH2-LEU-LtOMT for expression of both O-methyltransferases HsOMT and O-methyltransferases LtOMT, respectively. These expression constructs had previously been successfully prepared by our laboratory [19]. In the biotransformation procedure, the OMT vector was transformed into Sacharomyces cerevisiae BJ5464-NpgA host, and dropout minimal medium agar plates were used to select transformants on SC-Leu (yeast synthetic dropout medium without leucine). Recombinant yeast cells were cultured in $100 \mathrm{~mL}$ medium (containing $25 \mathrm{~mL}$ of the appropriate SC-Leu minimal dropout medium) to an OD600 of 0.6. The medium was then mixed with an equal volume of YPD medium (1\% yeast extract, $2 \%$ peptone, and $1 \%$ dextrose). Experimental flavonoids dissolved in dimethyl sulfoxide (DMSO) were also added to the cultures $(10 \mu \mathrm{g} / \mathrm{mL}$, final concentration), where appropriate, when the YPD medium was supplied. The fermentation temperature was maintained at $30^{\circ} \mathrm{C}$ with shaking at $220 \mathrm{rpm}$ for an additional $48 \mathrm{~h}$ until the wet cell weight reached $1.28 \pm 0.18 \mathrm{~g}$. The biotransformation efficiency was determined based on HPLC. 


\subsection{Extraction and Purification of the Products}

An equal volume of ethyl acetate was used to extract the fermentation cultures three times. Crude extract was first purified by silica gel column chromatography to obtain seven fractions (methanol/water 100:0, 90:10, 80:20, 70:30 60:40, 50/50, and 10/90, v/v), and subsequent extracts were dried in vacuo. Quantitative HPLC analysis was conducted on an AB SCIEX HPLC instrument equipped with a $\mathrm{C}_{18}$ column (Cosmosil YMC-Pack ODS-AM, 12, 20, and $250 \mathrm{~mm}$ ) to purify and obtain the target compound.

\subsection{Chemical Identification}

Samples were routinely analyzed using an AB SCIEX 4000 HPLC instrument (Waltham, MA, USA) applied onto an Agilent Eclipse Plus $C_{18}$ RRHD column $(1.8 \mu \mathrm{m}, 2.1 \mathrm{~mm} \times 50 \mathrm{~mm})$. Samples were first eluted using acetonitrile-water (10-95\%) for $20 \mathrm{~min}$ and then $95 \%$ (acetonitrile-water) for $10 \mathrm{~min}, 10 \%$ for $5 \mathrm{~min}$, and finally 10\% (acetonitrile-water) for $5 \mathrm{~min}$ with $0.5 \mathrm{~mL} / \mathrm{min}$.

\subsection{Structural Characterization of the Target Compound by LC-MS}

Products were first dried in vacuo and then restructured in methanol. HPLC-HRESI -MS and MS-MS spectra were acquired on an AB SCIEX HPLC coupled with an Agilent QTOF 6530 instrument (capillary: $3.6 \mathrm{kV}$, cone voltages: 40-150 V). The collision energy was $35 \mathrm{~V}$ and was calibrated each time with a standard calibration solution (Agilent) $(m / z$ 150-800).

\subsection{Structural Characterization of the Target Compound by NMR}

${ }^{1} \mathrm{H}$ NMR, ${ }^{13} \mathrm{C}$ NMR, HSQC, and HMBC (2D NMR) spectra were obtained using an Agilent 600 DD2 spectrometer. Per million (ppm) and $\mathrm{Hz}$ (J values) were considered chemical shift values $(\delta)$ and the coupling constants. The residual solvent peak of DMSO- $d 6$ were used as references for chemical shifts.

\subsection{Antimicrobial Biological Activity Assay}

Antimicrobial biological activities of the tested compounds were evaluated as Zhong et al., with some modifications [20]. Gram-positive and -negative bacteria and fungi (S. aureus ATCC6538, E. coli ATCC25922, and C. albicans SC5314) were selected for evaluation in the present study. S. aureus ATCC6538 and E. coli ATCC25922 were cultured with Luria-Bertani medium, while for C. albicans SC5314, potato dextrose broth medium was used for $24 \mathrm{~h}$ at $37^{\circ} \mathrm{C}$ (bacterial suspension in $1 \times 106 \mathrm{CFU} / \mathrm{mL}$ ). The experimental concentration ranges were from 75 to $400 \mu \mathrm{M}$. Each strain was cultured until an OD value of $0.6-0.8$ was reached and then diluted $1000 \times$. Each strain was, respectively, transferred into a 96-well plate at $100 \mu \mathrm{L} /$ well ( $90 \mu \mathrm{L}$ bacterial suspension and $10 \mu \mathrm{L}$ sample solution) after adding different concentrations of samples, followed by incubation for 12-16 h. The optical density at $650 \mathrm{~nm}\left(\mathrm{OD}_{650}\right)$ of C. albicans SC5314 was measured after TTC staining, while S. aureus ATCC6538 and E. coli ATCC25922 were stained for CCK8 before measurement. The minimal bactericidal concentration (MBC) and minimal inhibitory concentration (MIC) were simultaneously determined at a concentration of $15-400 \mu \mathrm{M}$.

\subsection{Antiproliferative and Cytotoxicity Activities Assay}

Analysis of the antiproliferative activity of the test compounds was performed according to Zhu et al. [21], with some modifications. MCF-7 human breast cancer cells were provided by the Cell Resource Center of the Chinese Academy of Sciences (Shanghai, China). Cell proliferation and cytotoxicity of anticancer activity were assessed using the methylene blue assay. For cell proliferation and cytotoxicity, MCF-7 cells were culture in a 96-well plate at $1.5 \times 10^{5}$ cells/well and at $3 \times 10^{5}$ cells/well, respectively. Various concentrations $(75-400 \mu \mathrm{M})$ of the test samples were added to a growth medium containing MCF-7 cells followed by cultivation for $16 \mathrm{~h}$. Following incubation for $72 \mathrm{~h}$, cell proliferation was 
measured with an absorbance of $570 \mathrm{~nm}$ using a microplate reader (Bio-Rad, Hercules, MA, USA), while cell cytotoxicity measurement was carried out $24 \mathrm{~h}$ after incubation.

\subsection{Data Analysis}

Data in present study were processed with one way ANOVA and Tukey's test by SPSS (Statistics for Social Science) version 17.0 (IBM, New York, NY, USA). The figure was conducted in GraphPad Prism 8.0.29 (GraphPad Software, San Diego, California, CA, USA). All experiments were conducted three times. Data were imported with mean $\pm S D$, and the significant differences were considered as $p<0.05$.

\section{Results}

\subsection{Biotransformation}

The two enzymes used for biotransformation, HsOMT and LtOMT, exhibited different catalytic abilities (Figure 1 and Table 1).
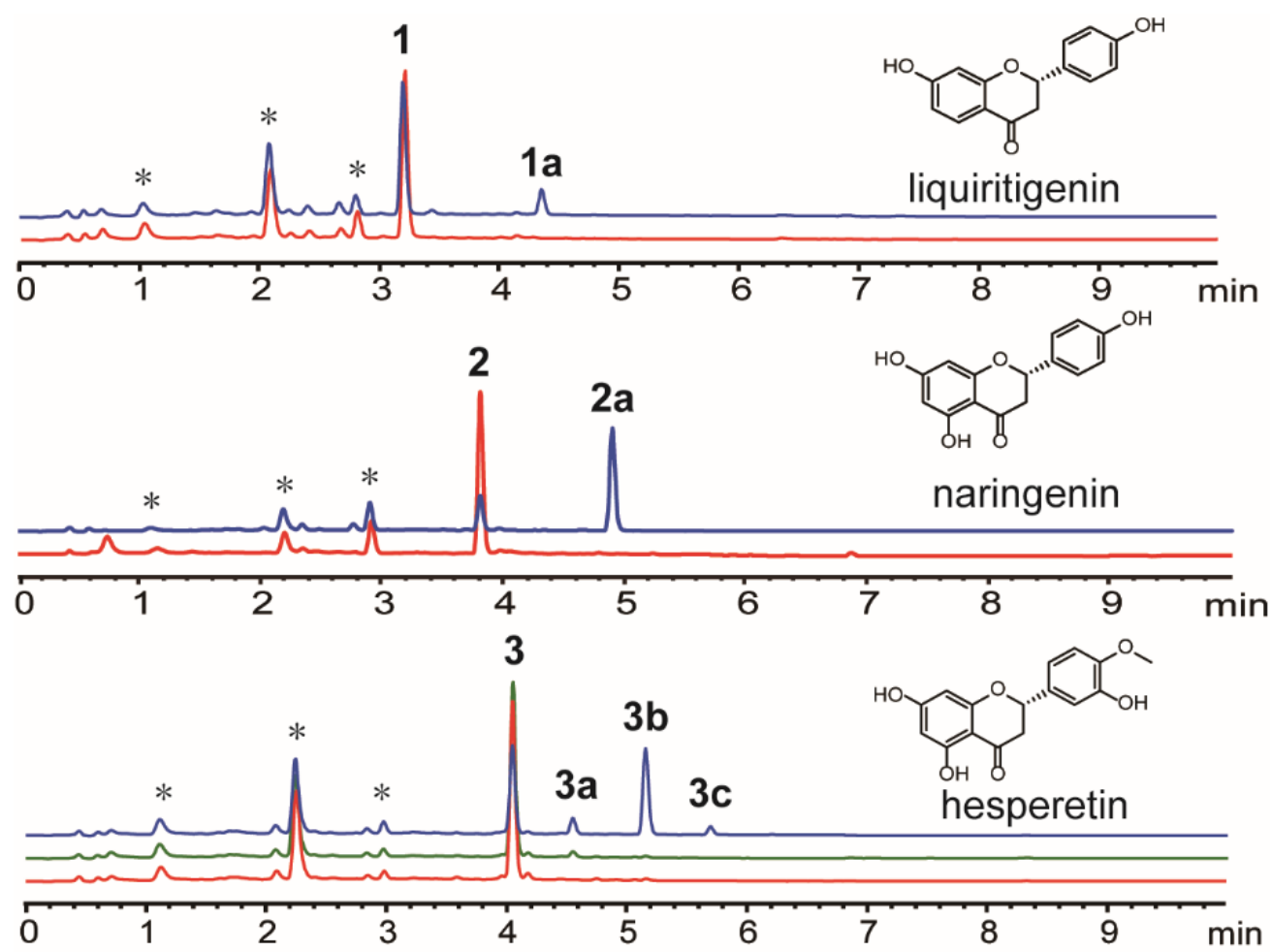

Figure 1. Biotransformation of flavonoid substrates by HsOMT and LtOMT. * represents equivalent endogenous substrate.

Table 1. Biotransformation products and yields of flavonoid substrates by Hs-OMT and Lt-OMT.

\begin{tabular}{ccccc}
\hline Number & Name & Biocatalytic Enzymes & Molecular Formula & Biotransformation Yield (\%) \\
\hline 1a & 7-methoxy-liquiritigenin & Hs-OMT & $\mathrm{C}_{16} \mathrm{H}_{14} \mathrm{O}_{4}$ & $15.64 \pm 1.61$ \\
2a & 7-methoxy-naringenin & Hs-OMT & $\mathrm{C}_{16} \mathrm{H}_{14} \mathrm{O}_{5}$ & $73.12 \pm 3.47$ \\
3a & 3'-methoxy-hesperetin & Hs-OMT & $\mathrm{C}_{17} \mathrm{H}_{16} \mathrm{O}_{6}$ & $8.42 \pm 1.33$ \\
3b & 7-methoxy-hesperetin & Lt-OMT & $\mathrm{C}_{17} \mathrm{H}_{16} \mathrm{O}_{6}$ & $3.73 \pm 0.84$ \\
3b & 7-methoxy-hesperetin & Hs-OMT & $\mathrm{C}_{17} \mathrm{H}_{16} \mathrm{O}_{6}$ & $43.81 \pm 0.02$ \\
3c & 7,3'-dimethoxy-hesperetin & Hs-OMT & $\mathrm{C}_{18} \mathrm{H}_{18} \mathrm{O}_{6}$ & $3.80 \pm 0.84$ \\
\hline
\end{tabular}

Liquiritigenin, naringenin, and hesperetin were catalyzed by HsOMT in Saccharomyces cerevisiae BJ5464-NpgA to obtain at least one product. Liquiritigenin was catalyzed by HsOMT in Saccharomyces cerevisiae BJ5464-NpgA to obtain one product, 1a, whose biotransformation yield was $15.64 \%$. Similarly, naringenin was catalyzed by HsOMT in 
Saccharomyces cerevisiae BJ5464-NpgA to obtain one product, 2a, whose biotransformation yield was $73.12 \%$. Hesperetin had three methylated products, two monomethylated isomers (3a and $3 b$ ), and one double methylated product (3c). Hesperetin was catalyzed by HsOMT and LtOMT to 7-methoxyhesperetin (Table 1).

The biotransformation yield of hesperetin was $51.34 \%$. NMR was measured to further characterize the structure. Liquiritigenin and naringenin were catalyzed by LtOMT but failed to obtain products explaining the regioselectivity of LtOMT, in which LtOMT is specific to the phenolic hydroxyl residing at the ortho position and the aromatic carbon bearing the carbonyl.

\subsection{Structure Characterization}

The structures of $1 \mathrm{a}, 2 \mathrm{a}, 3 \mathrm{a}, 3 \mathrm{~b}$, and $3 \mathrm{c}$ were elucidated by analyzing the NMR spectroscopic data of the purified compounds. Analysis of 1D and 2D NMR data (Figure 2, Tables 2 and 3) showed considerable similarities between the structures of $1 \mathrm{a}$ and glycyrrhizin, except for the absence of a methoxy group. In HMBC, correlation between 7-OMe $\left(\delta_{\mathrm{H}} 3.80\right)$ and aromatic carbon at $\delta_{\mathrm{C}} 165.67$ suggests that the methoxy group was located at C-7. Compound 1a exhibited similar NMR spectra (Table 2) to those obtained for 7methoxyglycyrrhizin. Therefore, the structure of 1a was assigned as 7-methoxyglycyrrhizin. In the same way, by comparing ${ }^{1} \mathrm{H}$ NMR and ${ }^{13} \mathrm{C}$ NMR of $2 \mathrm{a}$ with the corresponding substrate, naringenin, the presence of an additional methoxy group was observed. The positions of the methoxy groups of compounds $2 \mathrm{a}$ were determined at C-7 by HMBC correlation between 7-OMe $\left(\delta_{\mathrm{H}} 3.78\right)$ and aromatic carbon at $\delta_{\mathrm{C}} 167.45$ in 2a. The structure of 2a was finally elucidated as 7-methoxynaringenin. The positions of the methylation of compounds $3 \mathrm{a}, 3 \mathrm{~b}$, and $3 \mathrm{c}$ were located at $\mathrm{C}-3^{\prime}, \mathrm{C}-7$, and both $\mathrm{C}-3^{\prime}$ and $\mathrm{C}-7$, respectively, by comparing $1 \mathrm{D}$ and $2 \mathrm{D}$ NMR data for $3 \mathrm{a}, 3 \mathrm{~b}$, and $3 \mathrm{c}$ with those for their common substrate, hesperetin. Therefore, the structures of $3 a, 3 b$, and $3 c$ were determined to be 3'-methoxyhesperetin, 7-methoxy-hesperetin, and 3', 7-dimethoxyhesperetin, respectively.<smiles>COc1ccc2c(c1)O[C@H](c1ccc(O)cc1)CC2=O</smiles>

Figure 2. Structures of compounds 1a, 2a, 3a, 3b, and 3c, as identified by NMR. 
Table 2. ${ }^{1} \mathrm{H}(600 \mathrm{MHz})$ and ${ }^{13} \mathrm{C}$ NMR $(150 \mathrm{MHz})$ data of 1a and 2a in DMSO- $d_{6}$.

\begin{tabular}{|c|c|c|c|c|}
\hline \multirow{2}{*}{ No. } & \multicolumn{2}{|r|}{ 1a } & \multicolumn{2}{|r|}{$2 a$} \\
\hline & $\delta_{\mathrm{C}}$ & $\delta_{\mathbf{H}}($ Multi, $J$ in $\mathrm{Hz})$ & $\delta_{\mathrm{C}}$ & $\delta_{\mathrm{H}}(\mathrm{Multi}, J$ in $\mathrm{Hz})$ \\
\hline 2 & 79.26 & 5.48, brd $(13.4)$ & 78.65 & 5.48, brd $(14.8)$ \\
\hline $3 \alpha$ & 43.14 & $3.15, \mathrm{~m}$ & 42.05 & $3.30, \mathrm{dd}(17.1,14.8)$ \\
\hline $3 \beta$ & & $2.66, \mathrm{~m}$ & & $2.72, \mathrm{dd}(17.1,2.5)$ \\
\hline 4 & 190.42 & & 197.00 & \\
\hline 5 & 128.03 & $7.71, \mathrm{~d}(8.6)$ & 163.22 & \\
\hline 6 & 109.87 & $6.64, \mathrm{~d}(8.6)$ & 94.67 & $6.07, \mathrm{~d}(1.7)$ \\
\hline 7 & 165.67 & & 167.45 & \\
\hline 8 & 101.01 & $6.58, \mathrm{~s}$ & 93.81 & 6.10 , brs \\
\hline 9 & 163.30 & & 162.90 & \\
\hline 10 & 114.46 & & 102.62 & \\
\hline $1^{\prime}$ & 129.16 & & 128.70 & \\
\hline $2^{\prime}$ & 128.32 & $7.33, \mathrm{~d}(7.3)$ & 115.19 & $7.32, \mathrm{~d}(8.2)$ \\
\hline $3^{\prime}$ & 115.17 & $6.78, \mathrm{~d}(7.3)$ & 128.40 & $6.79, \mathrm{~d}(8.2)$ \\
\hline $4^{\prime}$ & 157.73 & & 157.79 & \\
\hline $5^{\prime}$ & 115.17 & $6.78, \mathrm{~d}(7.3)$ & 128.40 & $6.79, \mathrm{~d}(8.2)$ \\
\hline $6^{\prime}$ & 128.32 & $7.32, \mathrm{~d}(7.3)$ & 115.19 & $7.32, \mathrm{~d}(8.2)$ \\
\hline 7-OMe & 55.81 & $3.80, \mathrm{~s}$ & 55.92 & $3.78, \mathrm{~s}$ \\
\hline
\end{tabular}

Table 3. ${ }^{1} \mathrm{H}(600 \mathrm{MHz})$ and ${ }^{13} \mathrm{C}$ NMR $(150 \mathrm{MHz})$ data for $3 \mathrm{a}, 3 \mathrm{~b}$, and $3 \mathrm{c}$ in DMSO- $d_{6}$.

\begin{tabular}{|c|c|c|c|c|c|c|}
\hline \multirow{2}{*}{ No. } & \multicolumn{2}{|r|}{$3 a$} & \multicolumn{2}{|r|}{$3 b$} & \multicolumn{2}{|r|}{$3 c$} \\
\hline & $\delta_{\mathrm{C}}$ & $\delta_{\mathbf{H}}($ Multi, $J$ in $\mathbf{H z})$ & $\delta_{\mathrm{C}}$ & $\delta_{\mathrm{H}}($ Multi, $J$ in $\mathrm{Hz})$ & $\delta_{\mathrm{C}}$ & $\delta_{\mathrm{H}}$ (Multi, $J$ in $\left.\mathrm{Hz}\right)$ \\
\hline 2 & 78.48 & $5.48, \mathrm{dd}(12.5,2.4)$ & 78.41 & $5.48, \mathrm{~d}(11.4)$ & 78.70 & $5.53, \mathrm{dd}(12.6,2.1)$ \\
\hline $3 \alpha$ & 42.10 & $3.32, \mathrm{~m}$ & 42.13 & 3.26 , dd $(17.2,11.4)$ & 42.17 & $3.38, \mathrm{~m}$ \\
\hline $3 \beta$ & & $2.71, \mathrm{dd}(17.1,2.4)$ & & $2.75, \mathrm{~d}(17.2)$ & & $2.75, \mathrm{dd}(17.0,2.1)$ \\
\hline 4 & 196.22 & & 196.79 & & 196.86 & \\
\hline 5 & 163.46 & & 163.18 & & 163.20 & \\
\hline 6 & 95.85 & 5.89, brs & 94.63 & 6.08, brs & 94.71 & 6.09, brs \\
\hline 7 & 166.72 & & 167.42 & & 167.46 & \\
\hline 8 & 95.03 & 5.91 , brs & 93.82 & 6.11 , brs & 93.86 & 6.13, brs \\
\hline 9 & 162.82 & & 162.73 & & 162.79 & \\
\hline 10 & 101.73 & & 102.63 & & 102.61 & \\
\hline $1^{\prime}$ & 130.97 & & 130.97 & & 130.81 & \\
\hline $2^{\prime}$ & 110.61 & 7.13, brs & 114.08 & 6.93, brs & 110.62 & 7.14, brs \\
\hline $3^{\prime}$ & 148.72 & & 146.46 & & 148.74 & \\
\hline $4^{\prime}$ & 149.04 & & 147.92 & & 149.09 & \\
\hline $5^{\prime}$ & 111.54 & $6.98, \mathrm{~d}(8.1)$ & 111.96 & 6.94 , brs & 111.53 & $6.98, \mathrm{~d}(8.1)$ \\
\hline $6^{\prime}$ & 119.27 & $7.01, \mathrm{~d}(8.1)$ & 117.71 & $6.88, \mathrm{~d}(6.4)$ & 119.34 & $7.02, \mathrm{~d}(8.1)$ \\
\hline 7-OMe & & & 55.90 & $3.77, \mathrm{~s}$ & 55.94 & $3.79, \mathrm{~s}$ \\
\hline $3^{\prime}-\mathrm{OMe}$ & 55.58 & $3.77, \mathrm{~s}$ & & & 55.58 & $3.77, \mathrm{~s}$ \\
\hline $4^{\prime}$-OMe & 55.58 & $3.77, \mathrm{~s}$ & 55.67 & $3.77, \mathrm{~s}$ & 55.61 & $3.78, \mathrm{~s}$ \\
\hline 5-OH & & $12.14, \mathrm{~s}$ & & $12.10, \mathrm{~s}$ & & $12.11, \mathrm{~s}$ \\
\hline $3^{\prime}-\mathrm{OH}$ & & & & $9.10, \mathrm{~s}$ & & \\
\hline
\end{tabular}

\subsection{Antimicrobial Biological Activity}

The results of the antimicrobial biological activity assays of the samples are shown in Figure 3a-e. Three microbes (C. albicans SC5314, S. aureus ATCC6538, and E. coli ATCC25922) were considered in the assay for antimicrobial activity. Sample 1a effectively inhibited the growth of the three microbes. The strongest antimicrobial activity against S. aureus ATCC6538, C. albicans SC5314, and E. coli ATCC25922 was 1a at the dosage of 250,200 , and $400 \mu \mathrm{M}$, which increased by $148.77,765.64$, and $54.41 \%$ compared to liquiritigenin, respectively (Figure 2(1a-3c)). There was significant difference in the inhibition of C. albicans SC5314 and E. coli ATCC25922 by liquiritigenin, compared with 7-methoxy- 
liquiritigenin at the concentration of 75-400 $\mu \mathrm{M}(p<0.05)$. In particular, the antimicrobial 1 activity against E. coli ATCC25922 remained above $95 \%$ at the experimental concentration. However, naringenin and hesperetin were only observed to possess antimicrobial activity against C. albicans SC5314 (Figure 3d,e). From 75 to $200 \mu \mathrm{M}$, the antimicrobial activities of naringenin were higher than that of $2 \mathrm{a}$, while a reverse trend was observed when the concentration increased over $200 \mu \mathrm{M}$ (Figure 3d). The highest antimicrobial activity of $2 \mathrm{a}$ increased by $182.12 \%$ compared to that of naringenin (Figure $3 \mathrm{~d}$ ). The variations in the in vitro antimicrobial activities of hesperetin and its products $(3 a, 3 b$, and $3 c)$ are displayed in Figure 3e, which shows that 3a performed the best. The antimicrobial activities of sample $3 \mathrm{a}$ and $3 \mathrm{~b}$ increased with the increase in concentration, while $3 \mathrm{c}$ performed the best at $300 \mu \mathrm{M}$ (Figure 3e). Meanwhile, compared with that of the other products, the antimicrobial activity of $3 c$ sharply increased at concentrations higher than $250 \mu \mathrm{M}(p<0.05)$. The MIC and MBC of products were shown in Table 4.

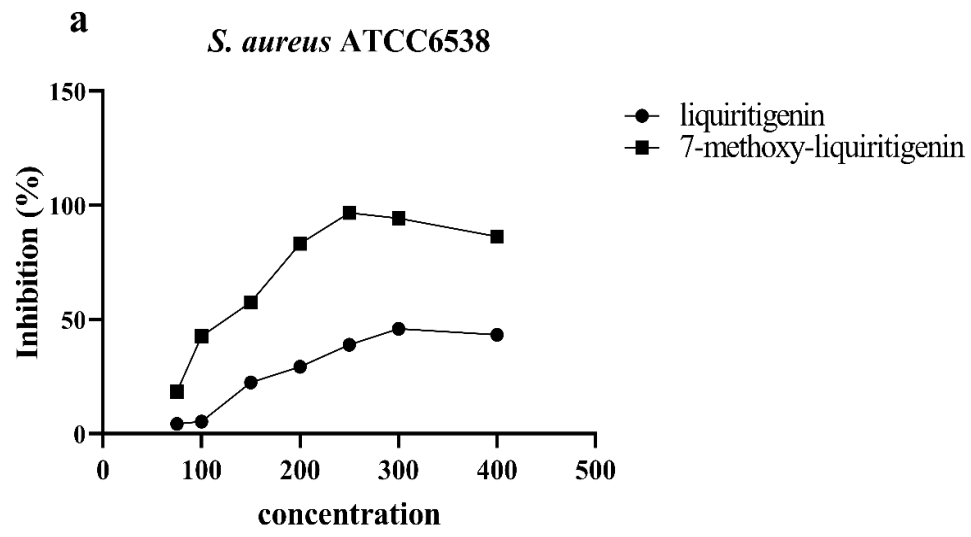

b C. albicans SC5314
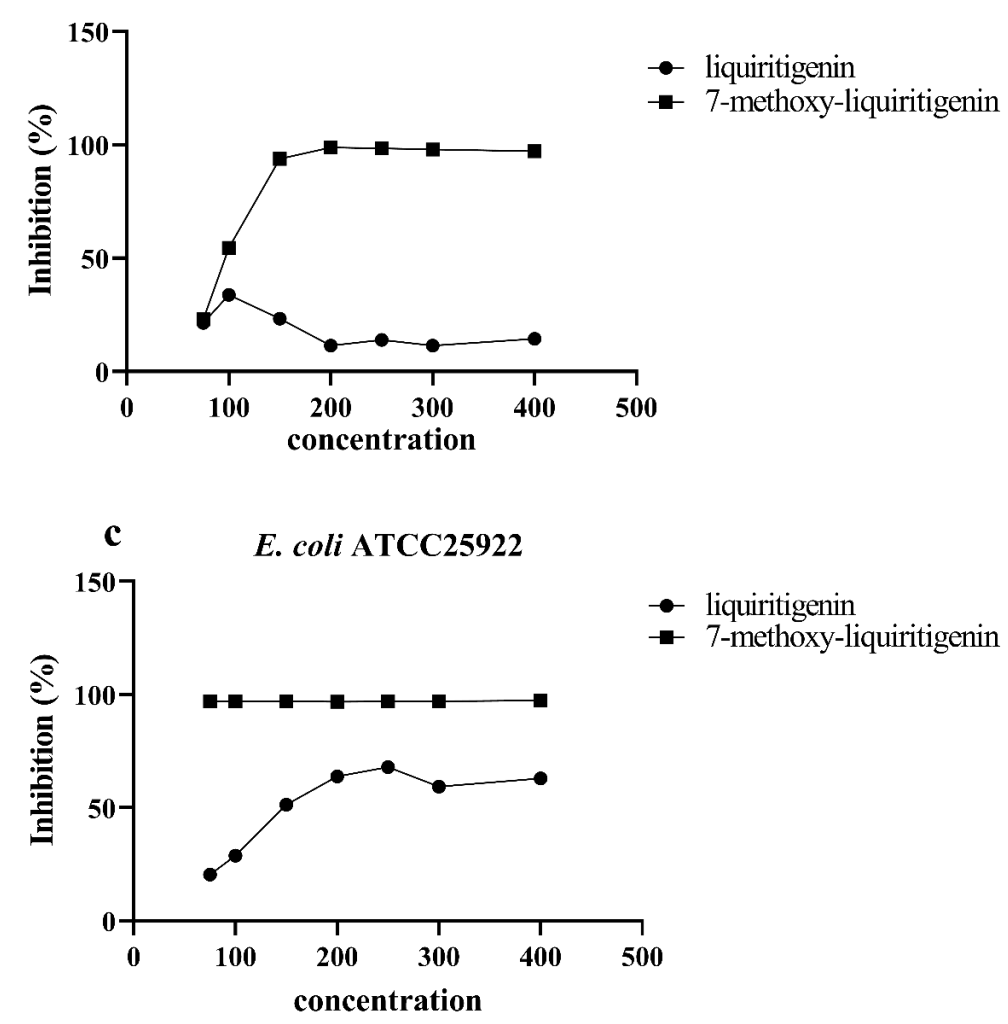

Figure 3. Cont. 

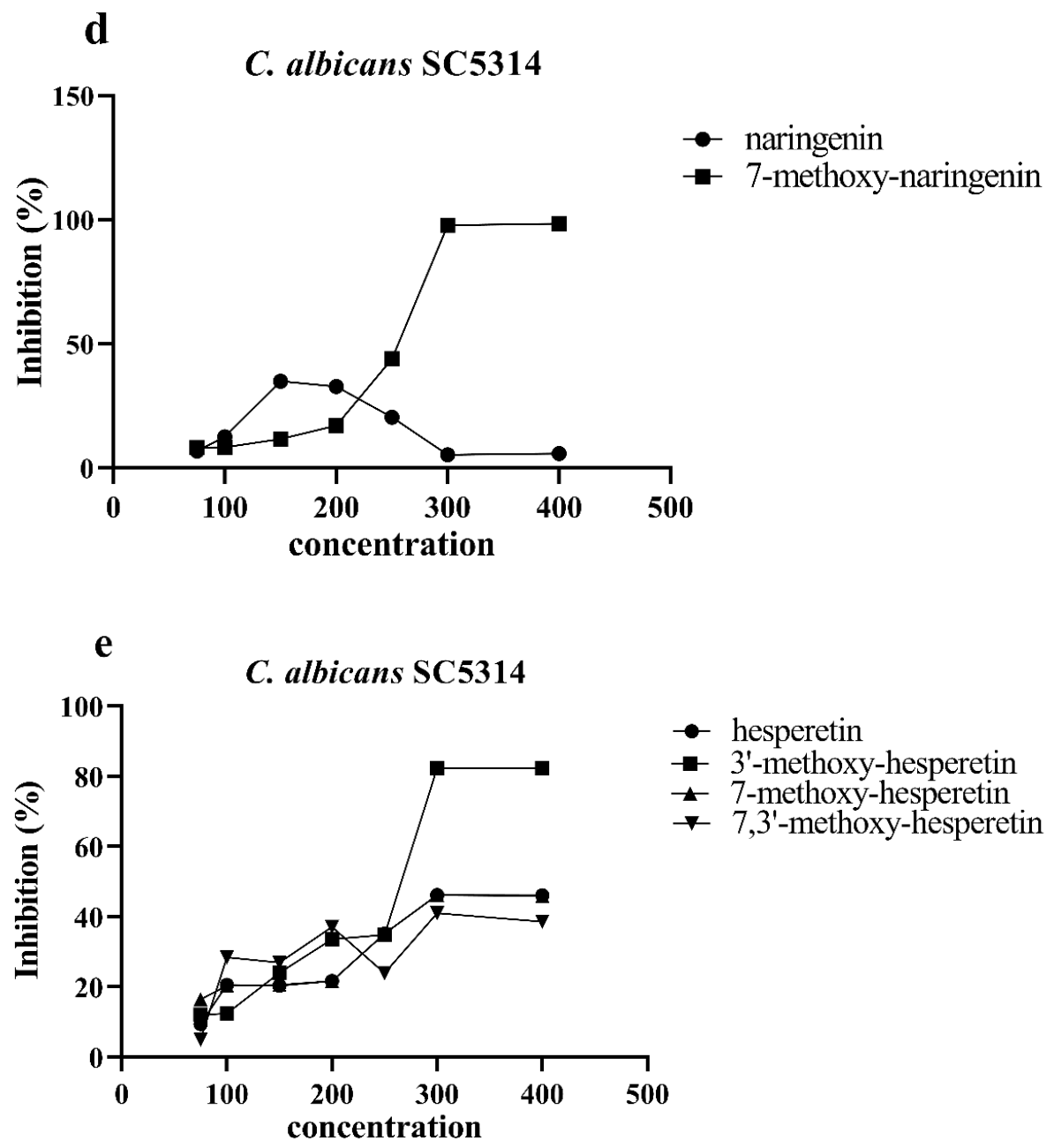

Figure 3. Inhibitory effect of $(\mathbf{a}, \mathbf{b})$ liquiritigenin and its methylated product 1 a on $S$ aureus ATCC6538, C. albicans SC5314, and E. coli ATCC25922; (c,d) naringenin 3 and its methylated product 2a on C. albicans SC5314; and (e) hesperidin and its methylated products 3a, 3b, and 3c on C. albicans SC5314. Data are presented as mean $\pm \mathrm{SD}$.

Table 4. MIC and MBC of samples to E. coli ATCC25922, S. aureus ATCC6538, and C. albicans SC5314.

\begin{tabular}{|c|c|c|c|c|c|c|}
\hline Compound & $\begin{array}{c}\text { E. coli } \\
\text { ATCC25922 } \\
\text { MIC } \\
(\mu \mathrm{M})\end{array}$ & $\begin{array}{c}\text { S. aureus } \\
\text { ATCC6538 } \\
\text { MIC } \\
(\mu \mathrm{M})\end{array}$ & $\begin{array}{c}\text { C. } \\
\text { albicans } \\
\text { SC5314 } \\
\text { MIC } \\
(\mu \mathrm{M})\end{array}$ & $\begin{array}{c}\text { E. coli } \\
\text { ATCC25922 } \\
\text { MBC } \\
(\mu \mathrm{M})\end{array}$ & $\begin{array}{c}\text { S. aureus } \\
\text { ATCC6538 } \\
\text { MBC } \\
(\mu \mathrm{M})\end{array}$ & $\begin{array}{c}\text { C. } \\
\text { albicans } \\
\text { SC5314 } \\
\text { MBC } \\
(\mu \mathrm{M})\end{array}$ \\
\hline 1 & 25 & 75 & 25 & $>400$ & $>400$ & $>400$ \\
\hline $1 \mathrm{a}$ & 15 & 75 & 25 & $>400$ & $>400$ & $>400$ \\
\hline 2 & - & - & 75 & - & - & $>400$ \\
\hline $2 a$ & - & - & 75 & - & - & $>400$ \\
\hline 3 & - & - & 75 & & & $>400$ \\
\hline $3 a$ & - & - & 50 & & & $>400$ \\
\hline $3 b$ & - & - & 25 & & & $>400$ \\
\hline $3 c$ & - & - & 75 & & & $>400$ \\
\hline
\end{tabular}




\subsection{Antiproliferation Activity}

MCF-7 cell proliferation was inhibited in a dose-dependent manner after exposure to liquiritigenin, naringenin, and hesperetin (Figure 4a-h, Table 5).

Table 5. Antiproliferative activities $\left(\mathrm{IC}_{50}\right)$ of the compound against MCF-7 human breast cancer cells (mean $\pm \mathrm{SD}, \mathrm{n}=3$ ).

\begin{tabular}{cc}
\hline Compound & IC $_{\mathbf{5 0}}(\boldsymbol{\mu M})$ \\
\hline 1 & $100.94 \pm 1.83$ \\
$1 \mathrm{a}$ & $11.23 \pm 0.60$ \\
2 & $125.53 \pm 2.76$ \\
$2 \mathrm{a}$ & $93.64 \pm 1.06$ \\
3 & $>150$ \\
$3 \mathrm{a}$ & $10.45 \pm 0.45$ \\
$3 \mathrm{~b}$ & $30.74 \pm 0.72$ \\
$3 \mathrm{c}$ & $31.00 \pm 1.44$ \\
\hline
\end{tabular}

\section{a}
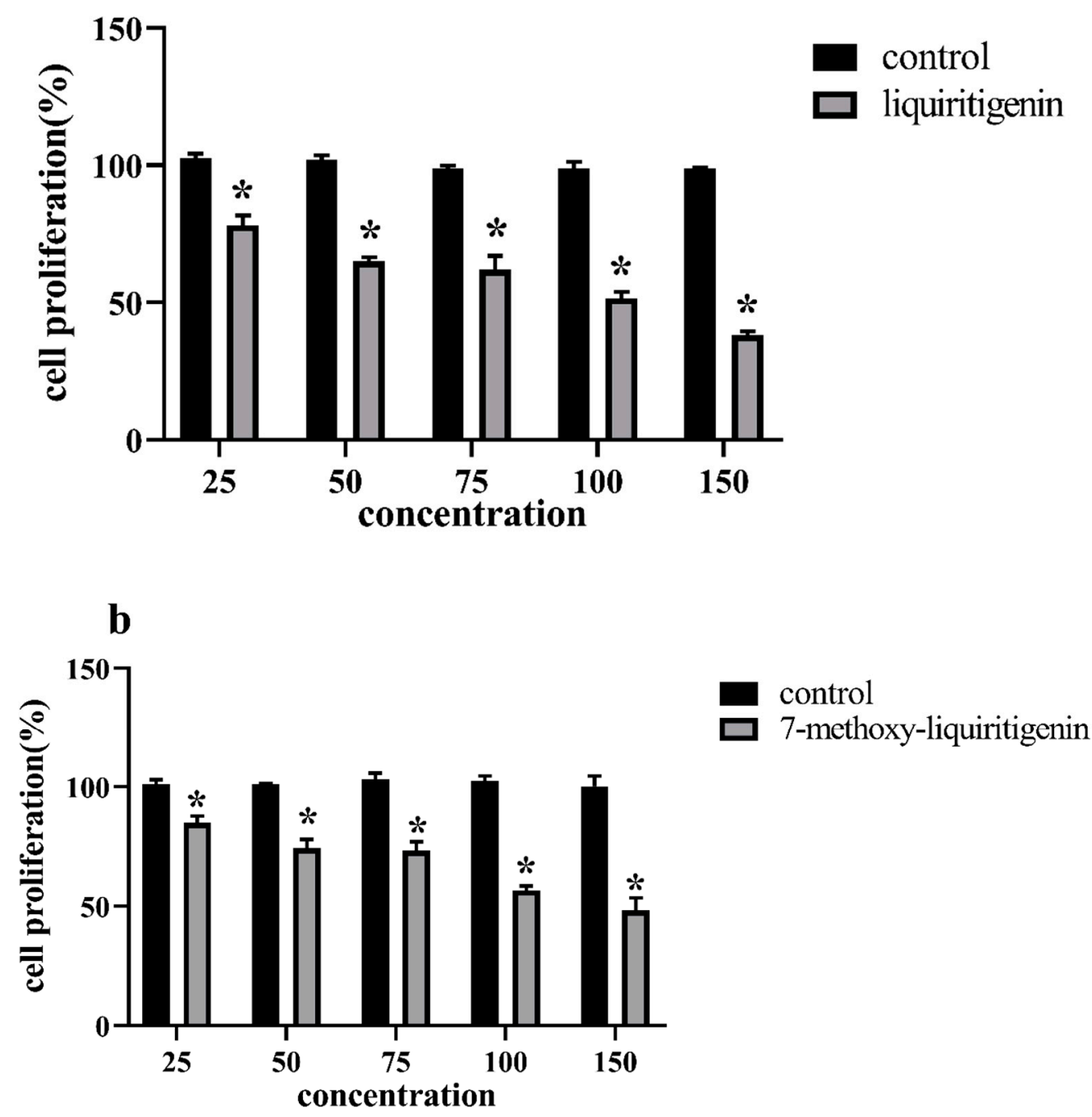

Figure 4. Cont. 

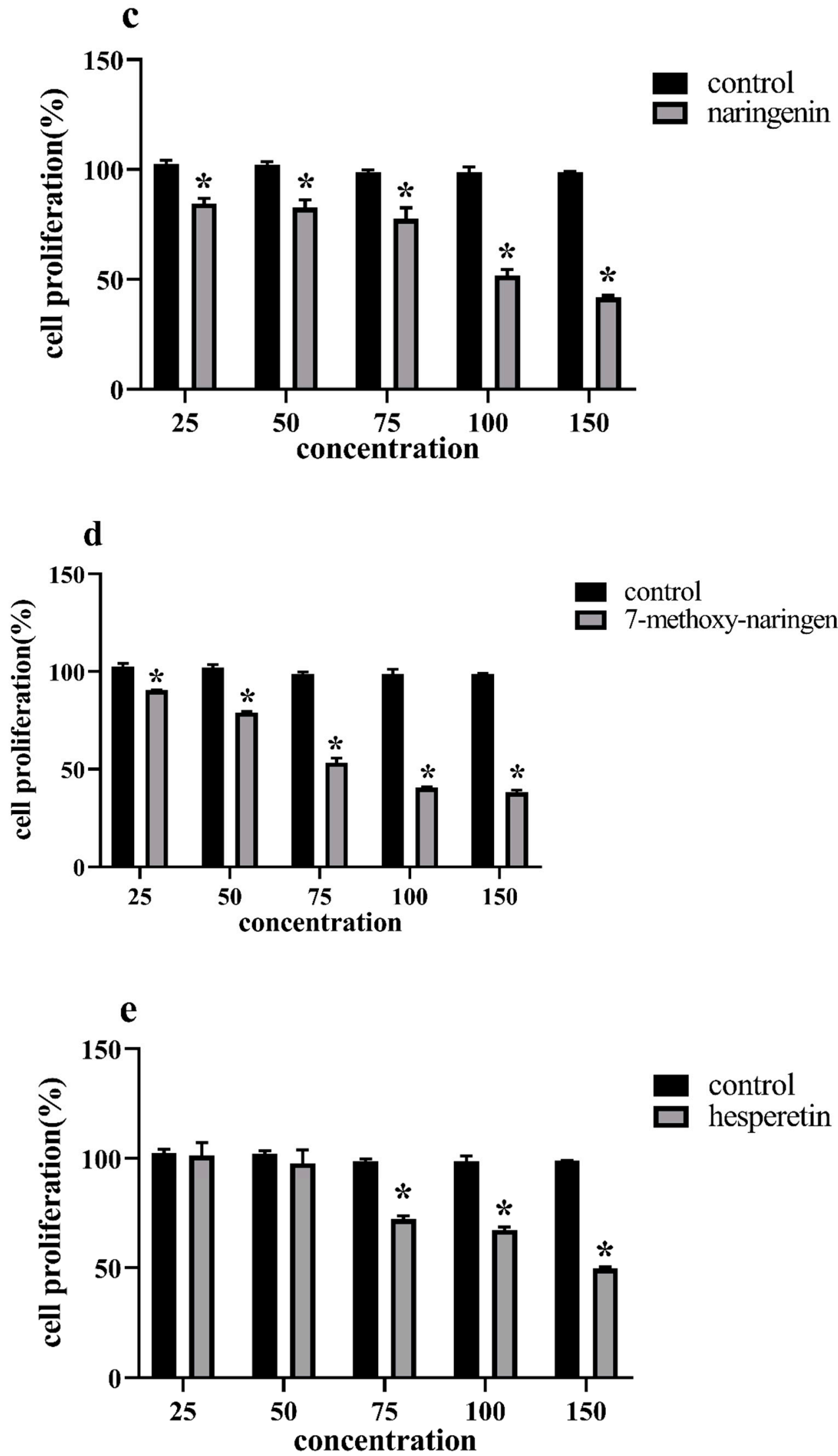

Figure 4. Cont. 

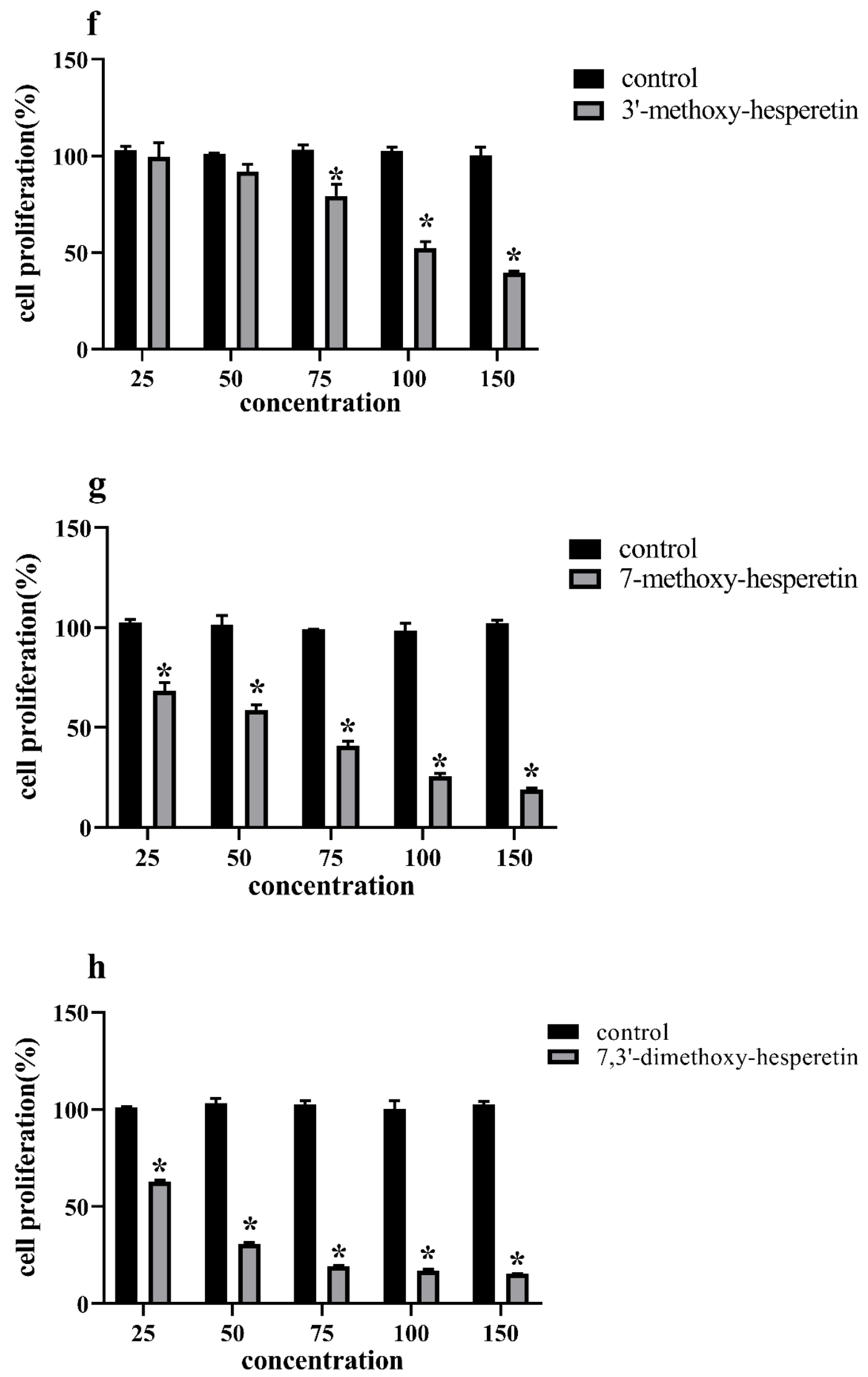

Figure 4. Inhibition of proliferation of MCF-7 human breast cancer cells by (a,b) liquiritigenin and 7-methoxy-liquiritigenin; (c,d) naringenin and 7-methoxynaringenin; and (e-h) hesperetin, 3'-methoxyhesperetin, 7-methoxyhesperetin and 7,3'dimethoxyhesperetin. (mean $\pm \mathrm{SD}, \mathrm{n}=3$ ). ${ }^{*}$ Indicates a significant difference compared to the control $(p<0.05)$. 
Cell proliferation was inhibited after exposure to liquiritigenin and 1a in a dosedependent manner (Figure $4 \mathrm{a}, \mathrm{b}$ ) (IC 50 of $100.94 \pm 1.83 \mu \mathrm{M}, 11.23 \pm 0.60 \mu \mathrm{M}$ ) (Table 5). Compared to liquiritigenin, the antiproliferation potency of compound 1a increased 8.99-fold. Naringenin 2 and 2a showed good antiproliferative activity compared to that of the control culture (Figure $4 c, d)(p<0.05)$. Cell proliferation was inhibited after exposure to naringenin and $2 \mathrm{a}$ ( $\mathrm{IC}{ }_{50}$ of $125.53 \pm 2.76 \mu \mathrm{M}, 93.64 \pm 1.06 \mu \mathrm{M}$ ). The antiproliferation potency of compound 2a was enhanced by 1.34-fold compared to that of naringenin. Methylation products of hesperidin $(3 a, 3 b$, and $3 c)$ resulted in products that showed comparable antiproliferative activities compared to the control $(p<0.05)$. Cell proliferation was inhibited after exposure to $3 \mathrm{a}, 3 \mathrm{~b}$, and $3 \mathrm{c}$, and their IC 50 values were $10.45 \pm 0.45 \mu \mathrm{M}, 30.74 \pm 0.72 \mu \mathrm{M}$, and $31.00 \pm 1.44 \mu \mathrm{M}$, respectively (Figure $4 \mathrm{e}-\mathrm{h}$, Table 5). The IC 50 was over $150 \mu \mathrm{M}$ for MCF-7 cells compared to the control $(p<0.05)$ (Table 5). Compound 3a showed 2.01- and 1.97 -fold increases in antiproliferation potency compared to that of $3 b$ and $3 c$, respectively.

\subsection{Cytotoxicity Studies}

The cytotoxicity of liquiritigenin, $1 \mathrm{a}$, naringenin, $2 \mathrm{~s}$, hesperetin, $3 \mathrm{a}, 3 \mathrm{~b}$, and $3 \mathrm{c}$ at a concentration corresponding to the IC ${ }_{50}$ on MCF-7 cells is shown in Figure 5. The cytotoxicity of $150 \mu \mathrm{M}$ hesperetin on MCF-7 cells is shown in Figure 4. No cytotoxicity was observed for 7-methoxyhesperetin on MCF-7 cells. Slight cytotoxicity was observed for liquiritigenin, naringenin, hesperetin, 7-methoxynaringenin, 7-methoxy-liquiritigenin, 3'-methoxyhesperetin, and 7, 3'-dimethoxyhesperetin on MCF-7 cells.

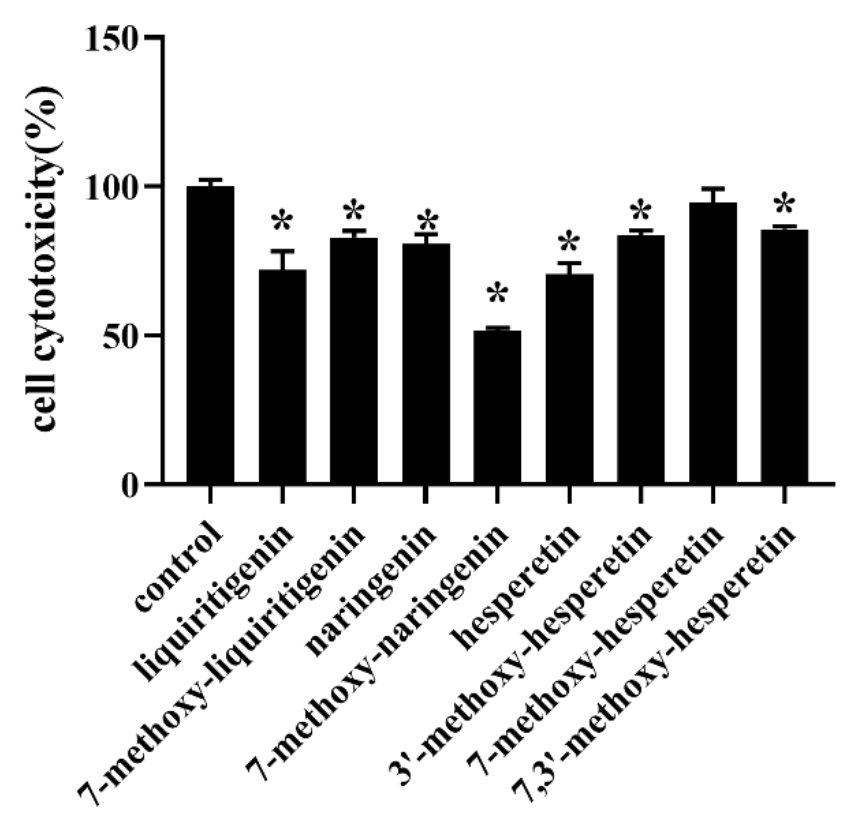

Figure 5. Cytotoxicity of liquiritigenin, 7-methoxy-liquiritigenin, naringenin, 7-methoxynaringenin, hesperetin, $3^{\prime}$-methoxyhesperetin, 7-methoxyhesperetin, and 7,3'-dimethoxyhesperetin on MCF-7 breast cancer cells (mean $\pm \mathrm{SD}, \mathrm{n}=3$ ). Data are presented as mean $\pm \mathrm{SD}$. * Indicates a significant difference compared to the control $(p<0.05)$.

\section{Discussion}

Flavonoids and their derivatives can potentially be used in clinical treatment due to their notable antimicrobial, anticancer, and anti-inflammatory effects [22]. Therefore, scientists are continuously developing technology such as for structural modification of flavonoids to alter their biological activities [11-14]. In the present study, LtOMT and HsOMT, as two orthologous O-methyltransferases (OMTs) in two fungal benzenediol lactones, were considered for carrying out biotransformation [19]. The enzymes HsOMT and LtOMT exhibited variable catalytic abilities in the modification of three substrates (liquiritigenin, naringenin, and hesperetin). NMR analysis found that, in 1a and 2a, the methyl 
group was added by HsOMT at the seventh position of liquiritigenin and naringenin, respectively, replacing the hydrogen in the hydroxyl group and becoming a methoxy group. However, three products were obtained in the reaction with hesperetin: $3 a$ (catalyzed by HsOMT); 3b (catalyzed by LtOMT); and 3c (catalyzed by LtOMT and HsOMT).

The bioactivity was significantly influenced by methylation [23], but not all the transformed products possessed the desired properties in the present study. Previous studies reported that pure naringenin showed poor antimicrobial activities, and free hesperetin also did not demonstrate activity against either E. coli or S. aureus [24,25]. Similarity, naringenin, hesperetin, and its methylation products $(2 a, 3 a, 3 b$, and $3 c)$ also failed to inhibit the growth of S. aureus ATCC 6538 and E. coli ATCC25922 in the present study. The effect of antimicrobial activities was particularly relevant to the conversion of highly hydrophilic groups and steric hindrance of reactive sites [26]. Magozwi et al. revealed that methylation of the hydroxyl groups on C-3 or C-7 reduced the antimicrobial activity of flavonoids [27]. Research on quercetin indicated that the loss of a hydroxyl group at C-3 was associated with low activity [27]. Here, the results for the methylation product of liquiritigenin on S. aureus ATCC6538, E. coli ATCC25922, and C. albicans SC5314 indicated that methylation did not lower the antimicrobial activity compared with liquiritigenin. In previous studies, liquiritigenin demonstrated a strong antibacterial effect on E. coli [28].

The anticancer ability of flavonoids has been the subject of great research interest in recent years. Previous studies focusing on anticancer abilities have demonstrated that MCF-7 breast cancer cell proliferation was inhibited in a dose-dependent manner after exposure to liquiritigenin, naringenin, and hesperetin [29-31]. Liquiritigenin was found to effectively inhibit the invasiveness of breast cancer cells by inhibiting DNA methyltransferase (DNMT) activity and increasing (breast cancer 1) BRCA1 expression [29], and naringenin treatment regulated endoplasmic reticulum (ER)-stress mediation to prevent breast cancer cell proliferation [32]. Meanwhile, hesperetin decreased the expression of aromatase and inhibited estrogen production in MCF-7 breast cancer cells [33]. The anticancer ability of flavonoids was influenced by the range of O-methylation, while the ability of methylated quercetin to inhibit HL60 leukemia cell proliferation was weaker than that of its unmethylated counterpart, and poly-O-methylated nobiletin and tangeretin showed the reverse trend in human squamous cell carcinoma [34]. Therefore, the anticancer performance of methylated flavonoids was variable and associated with the position of methylation and the type of cancer cell. Compounds 1a, 2a, 3a, 3b, and 3c also showed good performance in terms of anticancer activities. Katayama et al. reported that the methylation in 4-C of the B-ring was associated with promising potential in treating cancer [35]. However, $3^{\prime}$-O-methylation was also found to enhance the antiproliferative function of nobiletin, and the highly methylated flavonoid $3^{\prime}, 4^{\prime}, 7$-trimethoxyflavone showed better inhibitory activity against the breast cancer resistance protein compared to the minimally methylated acacetin. In the present study, $3 c$ displayed the best antiproliferation ability $[35,36]$. Interestingly, methylation products also showed good inhibition ability against MCF-7 breast cancer cells. The substrates in our study, for which a methyl group was added, appear to regulate some important functions in cell, such as gene regulation, epigenetics, and cellular energy status [34]. In addition to the antiproliferation ability of the methylation products, it is also worth discussing their toxicity. It has been reported that the existence of a 4-carbonyl group and 2-3 double bond is associated with cytotoxicity [37,38]. The cytotoxicity of the samples was demonstrated at the concentration of IC ${ }_{50}$. It can be clearly observed that $3 \mathrm{~b}$ and 2a showed the lowest and highest cytotoxicity among the samples, respectively. Naringenin had lower cytotoxicity than that of liquiritigenin, which was in accordance with the results of previous reports that the number of hydroxyl groups was negatively associated with cytotoxicity [39]. In fact, highly methoxylated products demonstrate higher toxicity than those that are less methoxylated, but the increase in hydroxyl groups decreased the hydrophobicity, thereby lowering product toxicity [39]. Therefore, products of hesperetin ultimately showed better performance in terms of cytotoxicity. 


\section{Conclusions}

The current study confirmed that three of the examined flavonoids tended to be transformed by HsOMT and not LtOMT. Among these compounds, naringenin was transformed by HsOMT with the highest conversion yield of $78 \%$. As a result, five known flavonoids were extracted and isolated from fermented cultures, and their structures were subsequently characterized by NMR. The results indicate that HsOMT easily methylates the free aromatic hydroxyl groups on ring A of flavonoids and could be developed as a regioselective biocatalyst for the methylation of phenolic natural products. The results of the antimicrobial experiment show that 7-methoxy-lliquiritigenin had the strongest inhibitory effect on C. albicans SC5314 and S. aureus ATCC6538, with MIC values of 25 and $75 \mu \mathrm{M}$, respectively, which were increased 3- and 1.25-fold compared to the unmethylated substrate. Additionally, 3'-methylhesperidin and 7-methylhesperidin had stronger inhibitory effects on C. albicans SC5314 than those of hesperidin and 7,3'-dimethylhesperidin. This may be due to the steric hindrance caused by the methylation of two hydroxyl groups of 7,3'-dimethylhesperetin, which affected the antimicrobial activity. From the experiment of antiproliferation and cell cytotoxicity assays on MCF-7 cells, it can be concluded that 7-methoxy-liquiritigenin had increased antiproliferative and cytotoxicity activities compared with liquiritigenin, and similar results were obtained for 7-methylnaringenin and naringenin. The results demonstrate that, compared with hesperetin, the derivatives 7-methylhesperetin, 3'-methylhesperetin, and 7,3'-dimethylhesperetin had an increased antiproliferation effect but decreased cytotoxicity, and that 7-methylhesperetin had no cytotoxicity. These results indicate that methylation can enhance the antimicrobial activity and antiproliferative effect of flavonoids. The current study provides an experimental basis for the further research on flavonoids as well as flavonoid-containing crops in the development of antimicrobial and anti-breast cancer drugs in addition to supplementary and health foods. Biotransformation is an ideal method, as it represents a means for the sustainable production of flavonoids.

Author Contributions: Y.H. and Z.W. (Zuchen Wei) contributed equally to this work. Resources, B.D.; conceptualization, B.D.; formal analysis, Z.W. (Zhi Wang) and Z.W. (Zuchen Wei); investigation, Y.H. and Z.W. (Zuchen Wei); methodology, Y.H. and Z.W. (Zuchen Wei); supervision, Z.W. (Zhi Wang) and G.L.; validation, Y.H. and Z.W. (Zuchen Wei); visualization, Y.H. and G.L.; writing-original draft, Y.H. and Z.W. (Zuchen Wei); writing-review and editing, Y.Y. and G.L.; funding acquisition, B.D. All authors have read and agreed to the published version of the manuscript.

Funding: This research was funded by the Agricultural Science and Technology Innovation Program (CAAS-ASTIP-2017-ICS).

Conflicts of Interest: The authors declare no conflict of interest.

\section{References}

1. Jang, D.; Jung, Y.S.; Kim, M.S.; Oh, S.E.; Nam, T.G.; Kim, D.O. Developing and validating a method for separating flavonoid isomers in common buckwheat sprouts using HPLC-PDA. Foods 2019, 8, 549. [CrossRef]

2. Cannas, M.; Pulina, S.; Conte, P.; Del Caro, A.; Urgeghe, P.P.; Piga, A.; Fadda, C. Effect of substitution of rice flour with quinoa flour on the chemical-ohysical, nutritional, volatile and sensory parameters of gluten-free ladyfinger biscuits. Foods 2020, $9, \mathbf{8 0 8}$. [CrossRef]

3. Irakli, M.; Lazaridou, A.; Mylonas, I.; Biliaderis, C.G. Bioactive components and antioxidant activity distribution in pearling fractions of different greek barley cultivars. Foods 2020, 9, 783. [CrossRef] [PubMed]

4. Siah, M.; Farzaei, M.H.; Ashrafi-Kooshk, M.R.; Adibi, H.; Arab, S.S.; Rashidi, M.R.; Khodarahmi, R. Inhibition of guinea pig aldehyde oxidase activity by different flavonoid compounds: An in vitro study. Bioorg. Chem. 2016, 64, 74-84. [CrossRef] [PubMed]

5. Bao, G.L.; Zhang, Y.L.; Yang, X.G. Effect of lemon peel flavonoids on anti-fatigue and anti-oxidation capacities of exhaustive exercise mice. Appl. Biol. Chem. 2020, 63, 1-11. [CrossRef]

6. Lin, Z.Y.; Lin, Y.Y.; Shen, J.X.; Jiang, M.J.; Hou, Y.M. Flavonoids in Ageratum conyzoides L. exert potent antitumor effects on human cervical adenocarcinoma HeLa cells in vitro and in vivo. Biomed. Res. Int. 2020, 4, 2696350. 
7. Qiu, J.; Jiang, Y.; Xia, L.; Xiang, H.; Feng, H.; Pu, S.; Huang, N.; Yu, L.; Deng, X. Subinhibitory concentrations of licochalcone A decrease alpha-toxin production in both methicillin-sensitive and methicillin-resistant Staphylococcus aureus isolates. Lett. Appl. Microbiol. 2010, 50, 223-229. [CrossRef]

8. Uzel, A.; Sorkun, K.; Oncag, O.; Cogulu, D.; Gencay, O.; Salih, B. Chemical compositions and antimicrobial activities of four different Anatolian propolis samples. Microbiol. Res. 2005, 160, 189-195. [CrossRef] [PubMed]

9. Vipin, C.; Saptami, K.; Fida, F.; Mujeeburahiman, M.; Rao, S.E.S.; Athmika; Arun, A.B.; Rekha, P.D. Potential synergistic activity of quercetin with antibiotics against multidrug-resistant clinical strains of Pseudomonas aeruginosa. PLoS ONE 2020, 15, e0241304. [CrossRef]

10. Cheng, M.; Yuan, F.Y.; Liu, J.L.; Liu, W.; Feng, J.F.; Jin, Y.; Tu, L.X. Fabrication of Fine Puerarin Nanocrystals by Box-Behnken design to enhance intestinal absorption. Aaps Pharmscitech 2020, 21, 1-12. [CrossRef]

11. Katsoura, M.H.; Polydera, A.C.; Tsironis, L.; Tselepis, A.D.; Stamatis, H. Use of ionic liquids as media for the biocatalytic preparation of flavonoid derivatives with antioxidant potency. J. Biotechnol. 2006, 123, 491-503. [CrossRef]

12. Mellou, F.; Lazari, D.; Skaltsa, H.; Tselepis, A.D.; Kolisis, E.; Stamatis, H. Biocatalytic preparation of acylated derivatives of flavonoid glycosides enhances their antioxidant and antimicrobial activity. J. Biotechnol. 2005, 116, 295-304. [CrossRef]

13. Lue, B.M.; Nielsen, N.S.; Jacobsen, C.; Hellgren, L.; Guo, Z.; Xu, X.B. Antioxidant properties of modified rutin esters by DPPH, reducing power, iron chelation and human low density lipoprotein assays. Food Chem. 2010, 123, 221-230. [CrossRef]

14. Hoang, T.K.D.; Huynh, T.K.C.; Nguyen, T.D. Synthesis, characterization, anti-inflammatory and anti-proliferative activity against MCF-7 cells of O-alkyl and O-acyl flavonoid derivatives. Bioorg. Chem. 2015, 63, 45-52. [CrossRef]

15. Araujo, K.C.F.; Costa, E.M.D.B.; Pazini, F.; Valadares, M.C.; de Oliveira, V. Bioconversion of quercetin and rutin and the cytotoxicity activities of the transformed products. Food Chem. Toxicol. 2013, 51, 93-96. [CrossRef] [PubMed]

16. Copmans, D.; Orellana-Paucar, A.M.; Steurs, G.; Zhang, Y.; Ny, A.; Fpubert, K.; Exarchou, V.; Siekierska, A.; Kim, Y.; De Borggraeve, W.; et al. Methylated flavonoids as anti-seizure agents: Naringenin 4',7-dimethyl ether attenuates epileptic seizures. in zebrafish and mouse models. Neurochem. Int. 2018, 112, 124-133. [CrossRef]

17. Xu, P.; Hua, D.; Ma, C. Microbial transformation of propenylbenzenes for natural flavour production. Trends Biotechnol. 2007, 25, 571-576. [CrossRef] [PubMed]

18. Xiao, Y.; Han, F.; Lee, I.S. Microbial transformation of licochalcones. Molecules 2020, 25, 60. [CrossRef] [PubMed]

19. Wang, X.J.; Wang, C.; Duan, L.X.; Zhang, L.W.; Liu, H.; Xu, Y.M.; Liu, Q.P.; Mao, T.L.; Zhang, W.; Chen, M.; et al. Rational reprogramming of O-methylation regioselectivity for combinatorial biosynthetic tailoring of Benzenediol Lactone Scaffolds. J. Am. Chem. Soc. 2019, 141, 4355-4364. [CrossRef] [PubMed]

20. Zhong, L.; Peng, L.; Fu, J.; Zou, L.; Zhao, G.; Zhao, J. Phytochemical, antibacterial and antioxidant activity evaluation of Rhodiola crenulata. Molecules 2020, 25, 3664. [CrossRef] [PubMed]

21. Zhu, Y.Y.; Yao, Y.; Shi, Z.X.; Everaert, N.; Ren, G.X. Synergistic effect of bioactive anticarcinogens from soybean on anti-proliferative activity in MDA-MB-231 and MCF-7 human breast cancer vells in vitro. Molecules 2018, 23, 1557. [CrossRef]

22. Liu, X.N.; Cheng, J.; Zhu, X.X.; Zhang, G.H.; Yang, S.C.; Guo, X.X.; Jiang, H.F.; Ma, Y.H. De Novo biosynthesis of multiple pinocembrin derivatives in Saccharomyces cerevisiae. ACS Synth. Biol. 2020, 9, 3042-3051. [CrossRef]

23. Alseekh, S.; de Souza, L.P.; Benina, M.; Fernie, A.R. The style and substance of plant flavonoid decoration; towards defining both structure and function. Phytochemistry 2020, 174, 112347. [CrossRef] [PubMed]

24. Ng, K.R.; Lyu, X.M.; Mark, R.; Chen, W.N. Antimicrobial and antioxidant activities of phenolic metabolites from flavonoidproducing yeast: Potential as natural food preservatives. Food Chem. 2019, 270, 123-129. [CrossRef] [PubMed]

25. Duranoglu, D.; Uzunoglu, D.; Mansuroglu, B.; Arasoglu, T.; Derman, S. Synthesis of hesperetin-loaded PLGA nanoparticles by two different experimental design methods and biological evaluation of optimized nanoparticles. Nanotechnology 2018, $29,395603$. [CrossRef] [PubMed]

26. Wen, W.; Jin, M.; Li, K.; Liu, H.; Xiao, Y.; Zhao, M.; Alseekh, S.; Li, W.; de Abreu, E.L.F.; Brotman, Y.; et al. An integrated multi-layered analysis of the metabolic networks of different tissues uncovers key genetic components of primary metabolism in maize. Plant J. 2018, 93, 1116-1128. [CrossRef]

27. Magozwi, D.K.; Dinala, M.; Mokwana, N.; Siwe-Noundou, X.; Krause, R.W.M.; Sonopo, M.; McGaw, L.J.; Augustyn, W.A.; Tembu, V.J. Flavonoids from the genus Euphorbia: Isolation, structure, pharmacological activities and structure-activity relationships. Pharmaceuticals 2021, 14, 428. [CrossRef] [PubMed]

28. Kong, W.J.; Zhao, Y.L.; Xing, X.Y.; Ma, X.P.; Sun, X.J.; Yang, M.H.; Xiao, X.H. Antibacterial evaluation of flavonoid compounds against E-coli by microcalorimetry and chemometrics. Appl. Microbiol. Biot. 2015, 99, 6049-6058. [CrossRef]

29. Liang, F.; Zhang, H.; Gao, H.; Cheng, D.; Zhang, N.; Du, J.; Yue, J.M.; Du, P.; Zhao, B.B.; Yin, L. Liquiritigenin decreases tumorigenesis by inhibiting DNMT activity and increasing BRCA1 transcriptional activity in triple-negative breast cancer. Exp. Biol. Med. 2021, 246, 459-466. [CrossRef]

30. Pateliya, B.; Burade, V.; Goswami, S. Enhanced antitumor activity of doxorubicin by naringenin and metformin in breast carcinoma: An experimental study. N S Arch. Pharmacol. 2021, 394, 1949-1961. [CrossRef]

31. Korga-Plewko, A.; Michalczyk, M.; Adamczuk, G.; Humeniuk, E.; Ostrowska-Lesko, M.; Jozefczyk, A.; Iwan, M.; Wojcik, M.; Dudka, J. Apigenin and hesperidin downregulate DNA repair genes in MCF-7 breast cancer cells and augment doxorubicin toxicity. Molecules 2020, 25, 4221. [CrossRef] 
32. Ajji, P.K.; Walder, K.; Puri, M. Combination of balsamin and flavonoids induce apoptotic effects in liver and breast cancer cells. Front. Pharmacol. 2020, 11, 574496. [CrossRef]

33. Rahideh, S.T.; Shidfar, F.; Nourbakhsh, M.; Hoseini, M.; Koohdani, F.; Entezam, M.; Keramatipour, M. The individual or combinational effects of Hesperetin and Letrozole on the activity and expression of aromatase in MCF-7 cells. Cell Mol. Biol. 2016, $62,38-43$.

34. Wen, L.R.; Jiang, Y.M.; Yang, J.L.; Zhao, Y.P.; Tian, M.M.; Yang, B. Structure, bioactivity, and synthesis of methylated flavonoids. Ann. N. Y. Acad. Sci. 2017, 1398, 120-129. [CrossRef]

35. Katayama, K.; Masuyama, K.; Yoshioka, S.; Hasegawa, H.; Mitsuhashi, J.; Sugimoto, Y. Flavonoids inhibit breast cancer resistance protein-mediated drug resistance: Transporter specificity and structure-activity relationship. Cancer Chemother. Pharmacol. 2007, 60, 789-797. [CrossRef]

36. Fan, X.; Bai, J.; Zhao, S.; Hu, M.; Sun, Y.; Wang, B.; Ji, M.; Jin, J.; Wang, X.; Hu, J.; et al. Evaluation of inhibitory effects of flavonoids on breast cancer resistance protein (BCRP): From library screening to biological evaluation to structure-activity relationship. Toxicol. Vitro 2019, 61, 104642. [CrossRef]

37. Brusselmans, K.; Bono, F.; Collen, D.; Herbert, J.M.; Carmeliet, P.; Dewerchin, M. A novel role for vascular endothelial growth factor as an autocrine survival factor for embryonic stem cells during hypoxia. J. Biol. Chem. 2005, 280, 3493-3499. [CrossRef] [PubMed]

38. Kitagawa, S.; Nabekura, T.; Takahashi, T.; Nakamura, Y.; Sakamoto, H.; Tano, H.; Hirai, M.; Tsukahara, G. Structure-activity relationships of the inhibitory effects of flavonoids on P-glycoprotein-mediated transport in KB-C2 cells. Biol. Pharm. Bull. 2005, 28, 2274-2278. [CrossRef] [PubMed]

39. Plochmann, K.; Korte, G.; Koutsilieri, E.; Richling, E.; Riederer, P.; Rethwilm, A.; Schreier, P.; Scheller, C. Structure-activity relationships of flavonoid-induced cytotoxicity on human leukemia cells. Arch. Biochem. Biophys. 2007, 460, 1-9. [CrossRef] [PubMed] 